\title{
Craft, textiles, and cultural assets in the Northern Isles: innovation from tradition in the Shetland Islands
}

\author{
Lynn-Sayers McHattie
}

The Glasgow School of Art, Scotland

I.mchattie@gsa.ac.uk

Katherine Champion

University of Stirling, Scotland

k.m.champion@stir.ac.uk

\section{Cara Broadley}

The Glasgow School of Art, Scotland

c.broadley@gsa.ac.uk

\begin{abstract}
This article explores design innovation approaches in the creative economy in the Northern Isles of Scotland, specifically, the Shetland archipelago, focusing on the textiles sector. Shetland has a rich history of craft work, including Fair Isle knitting and lace making. We contend that the value of cultural assets in contributing to the creative economy is underexamined and that there is a paucity of understanding of the innovative potential of craft and creative practitioners in the region. The insights presented are derived from Innovation from Tradition workshops, which aimed to reframe the creative economy within an island context, elicit knowledge surrounding local cultural assets and explore the innovative capabilities of creative practitioners. We reflect on how a design innovation approach allowed us to garner the collective wisdom held in communities and foreground the focal themes of practice, place and people.
\end{abstract}

Keywords: craft, creative economy, cultural assets, design innovation, Shetland Islands, textiles https://doi.org/10.24043/isj.47

(C) 2018 - Institute of Island Studies, University of Prince Edward Island, Canada.

\section{Introduction}

The Shetland archipelago is located $100 \mathrm{~km}$ north of Scotland, and the capital Lerwick is almost equidistant from Bergen in Norway as it is from Aberdeen in Scotland. It comprises about 300 islands and skerries, of which 16 are inhabited, with around $80 \%$ of the archipelago's population of 23,200 living on the main island (called Mainland) (National Records of Scotland, 2017). Traditionally the island economies have been reliant on agriculture and fishing, having received an economic boost over the past three decades as a result of public spending funded by the oil and gas industries. More recently, tourism has constituted an important source of income. Tourism has had a profound impact economically, socially and culturally on many island communities (Macleod, 2013). Shetland also has a rich history of craft work, including the internationally recognized traditions of Fair Isle knitting and lace making (Matarasso, 2012; Scott \& Marr, 2012). Despite this, it has been acknowledged that there is a lack of in-depth research on the creative industries and the region faces particular innovation challenges, including dispersed working communities and 
the attendant lack of technological infrastructure that can limit opportunities across the creative economy (HIE, 2013). Furthermore, within creative economy policy and academic research more broadly there has been a tendency to focus on global centres or formerly industrial cities in the process of restructuring, with a lack of attention on non-urban and, indeed, island-based creative activity. Islands are frequently characterized as remote and peripheral and therefore their communities often denied centrality (Grydehøj et al., 2015). As Alexander $(2016,2015)$ further asserts in relation to migration decisions within the Scottish islands, applying mainland models to island contexts risks obscuring the patterns we can see and understand.

The findings presented in this article are drawn from a series of Innovation from Tradition workshops, which aimed to better understand the creative economy specifically in island contexts, towards reimagining the innovative capabilities of craft and creative practitioners. In developing and delivering the workshops, we applied a design innovation approach. Building upon Frayling's (1993) comparisons of research - into, through and for art and design, our approach conceptualizes innovation through design as applying design methods and tools as interventions to bring about change in contextually located situations, and innovation of design as challenging established disciplinary principles and approaches in order to develop cultural assets and build creative capacity and capability. In turn, a design innovation approach is inspired by the democratic, inclusive and creative tenets of participatory design (Ehn, 2008; Sanders \& Stappers, 2008) as guiding principles for bringing together a diverse range of people with a shared interest or collective motivation, such as design practitioners, design researchers, multidisciplinary experts, entrepreneurs, end users, people and communities, and supporting them to collaboratively address a complex set of challenges through stages of exploration, ideation, and iteration (Norman \& Verganti, 2014). Sanders and Stappers (2014) assert that these practices allow for insights and ideas to be shared, developed and applied to inform new products, services and systems that respond to participants' experiences and aspirations. Positioning local people as central drivers of innovation, design innovation is aligned to an asset-based approach to identify existing skills, talents, and capabilities from within communities that may be hidden or ineffable (Foot \& Hopkins, 2010; Baker, 2014). In so doing, as McAra-McWilliam (2009, p. 70) suggests, "apparently disparate resources - intellectual, physical, social and material - can be usefully related to one another to create motivational, distributed enterprises within a regional ecology of cultural and economic activities." Characterized by tenets of inclusivity, collaboration and collectivity, a design innovation approach uses flexible and bespoke methods and tools to elicit dialogue around local cultural assets and foreground creative opportunities for enhancing societal wellbeing and economic regeneration.

This approach was embodied within the Innovation from Tradition workshops held in Shetland in autumn and winter 2016. The paper begins in the next section by exploring some existing understandings of the craft economy, introduces the Shetland archipelago as the context for this research and highlights the specific focus on the textiles sector. We then present the model of engagement with the craft sector, focusing on the design innovation approach undertaken in the Innovation from Tradition workshops, emphasizing the benefits of the asset-based, participatory and material aspects of this engagement. We argue that design innovation approaches have a role to play in examining and understanding the complex characteristics of craft production within an island context, and therefore can help support practitioners to identify collective challenges and opportunities surrounding the development and sustainability of their work. 


\section{Innovation from Tradition}

"Innovation from Tradition is a new approach to creative production that includes the past in the creation of present and future opportunities for islanders, particularly in terms of new ideas." (McAra-McWilliam, 2017).

The craft economy

Craft has recently been enjoying a resurgence (Jakob \& Thomas, 2015; Luckman, 2015, 2013, 2012). Frayling (2017) notes this is linked to the current economic climate and new modes of craft as production and the significance of craft as meaningful work (Crawford, 2009). Part of the reason for this, according to Sennett (2009), is that for human beings, craftsmanship, that is, the skill of doing things well, is the main source of human dignity. In his view craft is the combination of acquiring knowledge and skill from expert practitioners whilst experiencing it through practice. In this manner craft can be understood as the practice of making things as best we can (Frayling, 2017) based on an active and practical engagement with both the material and social worlds (Sennett, 2009). Adamson (2013, p. 172) positions craft as a mode of working whereby the knowledge exists in the practice through which tacit and practical knowledge are transformed into material form and are a "living part of a larger mechanical system." This re-emergence of craft into public debate sees craft increasingly recognized as a growing industrial sector with benefits linked to educational, cultural and economic policy agendas (Jakob \& Thomas, 2015). There is growing interest from policy makers who view craft as a stimulus to develop local and regional economies, skills and materials in relation to wider networks (Luckman, 2015, 2013; Marksuen, 2007; Nesta, 2007; Yair, 2011). Craft in this way is positioned as a conduit to the revitalization of local economies and as training mechanisms that support the creative economy: networking, apprenticeships, skills, training, mentoring, supporting micro-businesses, promoting new markets and fostering innovation (Jakob \& Thomas, 2015). A recent report (KPMG, 2016) commissioned by the Crafts Council asserts that craft skills and knowledge have a further potential of driving growth and innovation in other parts of the economy.

\section{Shetland cultural identity}

We contend that heritage and tradition underpin the production of cultural goods in Shetland, whereby culture is intrinsic in the mix as a feature of the total island (MacLeod, 2013) identity. From the beginning of Shetland's recorded history, the Northern Isles are considered to have a Norse culture. Shetland was integrated into the Norwegian state in about 875 and the Islands remained under Scandinavian rule until the mid-13 ${ }^{\text {th }}$ Century. Shetland passed over to Scotland in 1469. Due to Shetland's rich cultural heritage Shetlanders in the main relate to a Scandinavian, rather than Scottish, sense of culture and view themselves as a separate cultural identity with a distinct heritage and tradition. Grydehøj (2010, p. 78) posits that:

Tradition usually centres on 'customs, rituals and expressive form' and heritage on 'monuments, groups of buildings and sites' [...]. Tradition is thus an exclusive quantity: entrance into tradition requires a position in its genealogy, requires becoming part of the community of interlinking people that turns geography into place.

Textiles as cultural goods play a significant role in connecting communities to place based narratives and their symbolic production. Textiles have a rich tradition in Shetland as an expressive form from raw material manufacture, fibre and yarn production to hand and machine knitting, Fair Isle and fine lace, and weaving. Whilst the sector is small it provides cultural significance and value beyond its economic contribution, through its relations with tourism, growth of the creative industries and in providing employment (Scott \& Marr, 2012). 
The sector is predominately knitwear (garments and accessories) and characterized by SMEs, micro-businesses, sole traders and outworkers. It is dominated by micro-businesses, with over $70 \%$ sole traders having a turnover of less than $\mathcal{E}^{25,000}$ per annum (Scott \& Marr, 2012, p. $15)$ with the majority of these heavily reliant on local and tourist markets.

Significantly, in recent years, the production capacity of the knitting sector has declined, with a decrease in the numbers of skilled knitters and linkers. Notably, what has changed is the environment in which knitters operate. A 1984 study observed "near 2000 people knitting at home $[\ldots]$ supplementing their incomes, attracting earnings [...] and continuing a craft which has contributed favourably so long to maintaining Shetland's home based family and community spirit" (Scott \& Marr, 2012). Recent estimates suggest around half that number of home workers due in part to an ageing workforce and low wage rates. This has led to a reduction in production capacity and skills, or what we term process wisdom (McAraMcWilliam, 2017) in the sector, which together with a lack of investment in and focus on design (Scott \& Marr, 2012) presents a particular innovation challenge. More broadly within the creative economy, longstanding challenges around the craft sector continue to persist, including the provision of business training and business support services; raising public understanding of the skills, time and effort that go into creating craft objects and appreciation of their true value; the ability to reach prospective clients for niche or particularly expensive works; and the identification and development of markets both at home and overseas (DCMS, 1998). There is also a tendency to denigrate craft work with high proportions of informal labour, issues around measuring the sector and a view of the sector as hobbyist (Luckman, 2018; The Crafts Council, 2015). A further tension around negotiating authenticity and nostalgia within rural creative work with a rich heritage whilst also supporting innovation has also been identified, and chimes with what Luckman (2012, p. 8) terms the "the hegemony of the rural idyll."

\section{Harnessing collective wisdom}

Our overarching aim is to explore the innovative capabilities of craft and creative practitioners in an island context, with a focus on textiles, towards repositioning understandings of an island creative economy. Whilst much has been written, inter alia, on Fair Isle knitting and gender in Shetland (Abrams, 2006) and knitting from a textile history perspective (Blackman, 1998), we are interested in the practice of knitting beyond an historical perspective and situate knitting as a material practice and textiles as a form of cultural production. Textile practices, such as knitting, are important sources of island identity, cultural appreciation and deep process wisdom. In this manner knitting embodies a complex system of cultural meanings that confer to aesthetics of practice, place as location and articulate a nexus of social relations. To speak of knitting is to speak of a mode of cultural production and describe it not simply as a reflection of some essentialist culture but as an arena for the constant process of negotiating the meanings that constitute culture and in so doing is intrinsic to the fabric of Shetland life. Rather than presenting a unified, hegemonic position, textile practices reflect an ongoing dialogue between the past, the present and the future through a multitude of countervailing cultural meanings (Thompson \& Haytko, 1997).

Innovation from Tradition was predicated on better understanding collective wisdom, what we refer to as the stock of shared knowledge and practices held in common by groups or communities, such as those populating non-metropolitan regions and islands, as a resource for innovating or revitalizing their way of life. This conception does not ignore or seek to diminish the socio-cultural variety of island communities (Macleod, 2013), a critique sometimes levelled at those selecting to research them with a perception that they are home to a discrete, self-contained and somewhat homogeneous group of people. Communities can imbue island sites with traditional importance (Grydehøj, 2010) and cultural meaning. From patterns, styles and motifs through to techniques, objects, practice and execution, the 
development of textiles as cultural assets is rich in tradition. Innovation from Tradition sought to harness the collective wisdom in communities as a form of shared cultural capital. Whilst Innovation from Tradition may be viewed as paradoxical in nature, this collective wisdom can contribute to economic production, social organization and cultural identity.

Innovation from Tradition built on the team's experience of using design-led approaches to promote the creation of innovative business ideas, processes and models (Broadley et al., 2016; Johnson et al., 2016; Kearney \& McHattie, 2014). By engaging with the craft practices of making and the materiality of design tools as artefacts, the project encouraged engagement and provided space for innovation towards enhancing and sustaining the creative economy in non-urban geographies. As well as arguing for the innovative potential of craft and creative practitioners, we contend that, despite a characterization of non-urban areas as challenged, rural and remote, and islands as the ultimate non-urban areas, these contexts can offer creative opportunities to develop economic production, social networks and cultural capital in new and innovative ways.

\section{Design innovation: a methodological approach}

Bridging our disciplinary concerns and methodological stance, the design innovation approach draws from Participatory Action Research (PAR) (Chevalier \& Buckles, 2013). Centred on the relationships formed between researchers, practitioners, communities and organizations, PAR draws from experiential learning and domain-specific expertise to offer a framework for conceptualizing new knowledge and insights for innovation within research contexts (Howard \& Somerville, 2014). Whilst originating from the field of organizational behaviour and prevalent across the social sciences, PAR is often adopted in participatory design studies, in which the design process entails iterative cycles of action and reflection in response to dialogue and interactions (Howard \& Somerville, 2014; Bilandzic \& Venable, 2011). In this project, a flexible PAR framework allowed us to bring together a multidisciplinary team of designers, craft and creative practitioners, researchers, and regional development agents to identify collective resources towards reframing future innovation opportunities.

\section{Participatory design: what it is and what it could be}

Designers and design researchers working in participatory design employ creative, generative, visual, and participatory methods - including collaging, sketching, 3D modelling tasks, prototypes and design games - as ways of engaging with participants and telling, making, and enacting to envisage the future (Brandt et al., 2012). Steen (2011) positions participatory design as a practice in which designers and researchers devise methods to engage with users and stakeholders to understand their experiences and consider how these can be enhanced. Following Dorst's Frame Creation model, critical engagement with existing situations within the design context can illuminate both "significant influences on their behaviour and what strategies they currently employ" and "practices and scenarios that could become part of the solution" (Dorst, 2015, p. 76). Such activities build on primary knowledge and expertise ("what is") to imagine preferable scenarios ("what could be") (Steen, 2011, p. 50).

Vaajakallio (2009) has evaluated the generative nature of collaborative design activities and proposed that this fundamentally social and embodied practice originates from the dialogue that emerges when participants enact and describe their existing experiences through creative, expressive methods. In developing notions of context-specific participatory design methods, there is a need for designers and researchers to immerse and embed themselves within the geographical setting in which their projects are situated, allowing them to develop rich and authentic understandings of the social, cultural, political and economic conditions that characterize each unique design context. 
An asset-based approach

In the context of public service reform and achieving a more equal society in Scotland, practices of co-production emphasize the role of local government agencies in actively supporting individuals and communities to participate in a democratic process and contribute their experiences and ideas to design and develop responsive new services, systems, and forms of delivery (Housden, 2014). Aligned with this vision and having been adopted across areas of public health improvement, community development, and social services (Garven et al., 2016), an asset-based approach "values the capacity, skills, knowledge, connections and potential in a community" (Foot \& Hopkins, 2010, p. 17) as a means of reframing future opportunities (Baker, 2014; Glasgow Centre for Population Health (GcPH) and Scottish Community Development Centre (SCDC), 2015). Emphasizing the role of individuals, communities, and organizations as rich resources of knowledge, experience, and skill that can contribute to enhancing society and eventually lead to less dependency on professional services, asset-based approaches "focus on nurturing engagement and relationship building to enable strengths, capacities and abilities to be identified and developed for positive outcomes" (GcPH \& SCDC, 2015, p. 15). In turn, asset-based approaches use flexible, appreciative (Whitney \& Trosten-Bloom, 2010) participatory activities such as asset mapping, conversation cafés and community walkabouts to strengthen positive dialogue and articulate connections within communities and services (GcPH \& SCDC, 2015).

With a focus on emergent interaction, the fluid nature of our design innovation approach allowed for specific methods, tools, and techniques to emerge from our immersion in the Shetland Isles creative economy context and these were shaped by our interactions with the participants and stakeholders. We now go on to discuss the methods used in the Innovation from Tradition workshops that were designed with the aim of eliciting dialogue around these local cultural assets.

\section{Innovation from Tradition workshops}

Focusing on Scotland's Northern Isles (the archipelagos of Orkney and Shetland), the Innovation from Tradition pilot series of workshops were delivered in partnership with the regional development agency, Highlands and Islands Enterprise (HIE). These were a series of two interlinked workshops (with a three-week intervening period), which aimed to explore and inspire innovation and future opportunities for the islands' craft and creative industries sectors. The workshops foregrounded questions around the role design can play in innovating craft practices and in enabling and sustaining the creative economy in rural geographies.

\section{Preparatory Scoping}

Considerable time, planning and collaborative work was involved in designing the workshops. Scoping visits were initiated around a year in advance of the workshop delivery to engage with gatekeepers and intermediaries from cultural institutions as well as craft and creative practitioners. In tailoring the workshop approach, a number of key decisions were made. Firstly, it was decided that, rather than a sole focus on textiles, the workshop scope would be extended to include a broad range of craft and creative industry activities. This was based on the aspiration for cross-sectoral knowledge exchange. Secondly, there was a strong emphasis during the planning process (driven particularly by the regional development agency gatekeepers who were familiar with most of the participants) on the workshops providing an opportunity for capacity building and professional development to address issues of confidence amongst participants. 
The workshops

At the workshops carried out in Lerwick, the main town in Shetland, during autumn and winter 2016, there were 18 participants drawn from a range of craft and creative industries including textiles, design, architecture, soap making, jewellery, film and media and print making. Through a series of interactive sessions, the participants were introduced to working with design innovation tools and processes that could be used to build up thoughts on how innovation challenges could be defined, understood, and addressed; were encouraged to experiment with alternative ideas; and explored how to develop genuinely innovative concepts.

The intention was to create an intensive and immersive experience, purposefully constructed to encourage reflection on and sharing of existing assets and resources. Facilitators and experts in relevant fields supported participants throughout the workshops in addition to challenging positions and perspectives. The workshops were designed to be a valuable experience in and of themselves and included elements of continuous professional development, for example, including advice on pitching and presenting as well as contributions from industry specialists in the field of craft, innovation and creative practice and experts on creative industries support and funding.

\section{Wisdom Wall}

In order to support participants through stages of exploration, ideation, and iteration in the workshops, we recognized the importance of developing design tools that reflected the local context of craft and creative practices in the Northern Isles. One such tool was the Wisdom Wall. Participants were asked to complete Wisdom Wall cards (Figures 1 \& Figure 2) during the workshop to share existing assets and resources. These cards were themed as follows:

- People (organization or location): Who and where? What makes them inspiring?

- Projects: What and where? What makes it inspiring?

- Practices (skills, industries or interests): What is it? What is it being used for?

- Place: Where is it? What makes it inspiring?

- Technologies: What is it? What is it being used for?

- Materials: What is it? What makes it valuable?

- Wildcard: Any other suggested resources that do not fit the above categories. 


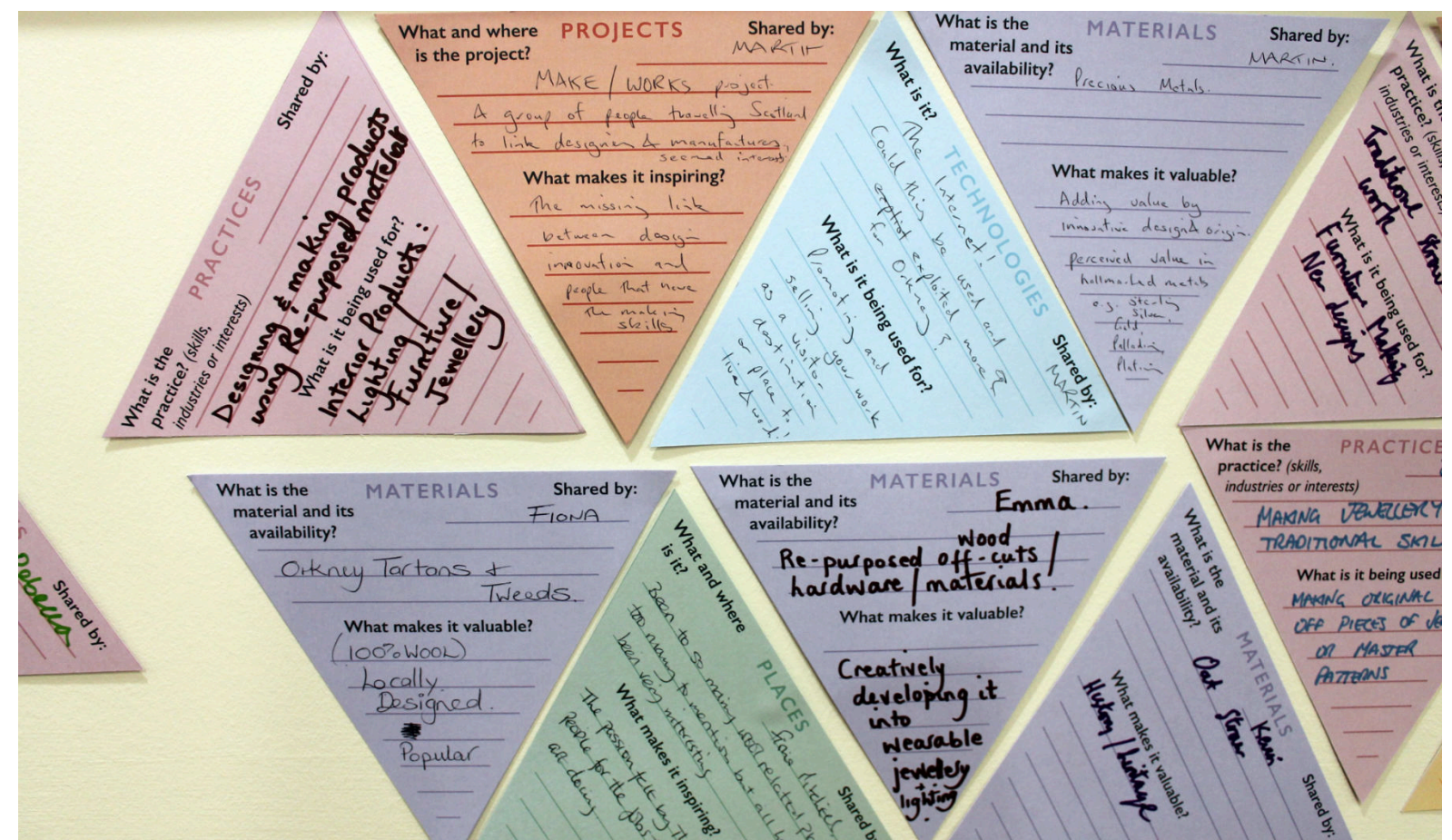

Figure 1: Wisdom Wall cards were provided to participants to categorize and capture their knowledge and insights into existing resources that could be useful in inspiring ideas around innovation of the craft and creative sectors in Shetland.

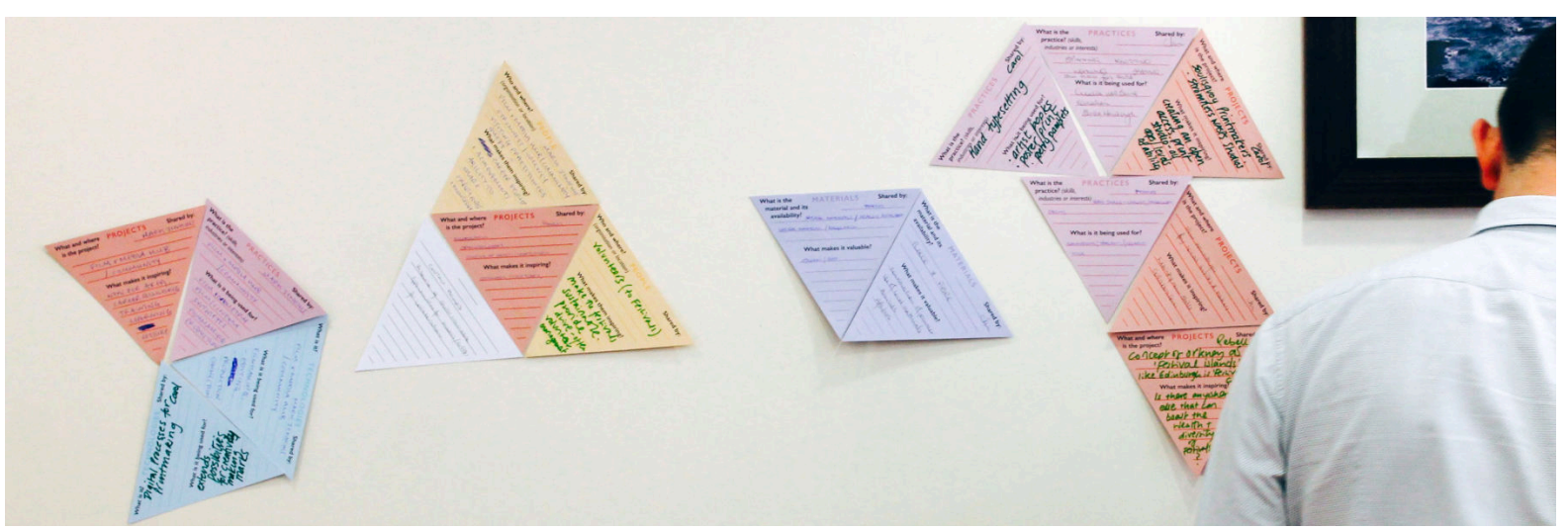

Figure 2: Once completed, the Wisdom Wall cards were clustered by participants to represent potential new configurations of resources.

These were then tessellated by participants and clustered around key themes or related areas. By adopting an asset-based mindset, the Wisdom Wall cards mobilized the skills, talents, knowledge, and connections from within communities and organizations situated in Shetland and supported participants to reframe these in response to future innovations.

\section{Participant voice}

During the workshops, the project team recorded key aspects of the discussion in written notes and participant quotes. The materials including the Wisdom Wall cards and other design artefacts were preserved and photographed to form an assets archive (Figures 1 \& 2). The Wisdom Wall elicited a rich range of responses and revealed in conversation with participants what they regarded as valuable collective assets and the participants' voice is threaded through the initial insights sections. 


\section{Initial insights}

From the synthesis of these resources and reflections from the field notes, three emergent focal themes (practice, place and people) were highlighted as the loci of concentration from the set of seven Wisdom Wall cards and the excerpts from the participants' discussions. These three themes resonate with the findings of Burnett and Harling Stalker (2016) in their research into the experiences of cultural workers in Scottish island communities, which found them balancing cultural heritage and tradition, with new interpretations of islandness across people, place and practice. Through connecting practice as process wisdom, place as living wisdom, and people as a meshwork (Ingold, 2013) of collective wisdom, we now proceed to outline the initial insights from the workshops as a shared stock of assets and a form of collective cultural capital.

\section{Practice: process wisdom}

We position practice as a form of materiality that exemplifies deep process wisdom through craft technique and creative expression. Existing research accounts have identified the complex interplay between material practices and socio-economic and cultural histories of island communities. Such historical accounts are extremely valuable in challenging traditional views of material practices (for example knitting) and, importantly, how they have integrated women into the market (Abrams, 2006). It is axiomatic that island craft techniques, practices and processes are historically located. For example, Fair Isle knitting is inextricably linked to history and heritage on the Shetland island of Fair Isle. Workshop participants mentioned "mending, grafting, linking" as key knitwear manufacture and hand knitting skills in Shetland. They also mentioned "outworkers and home machine knitters" as a less visible, but important traditional Shetland skills base and one they feared was at risk of being lost. The term "heritage knitting' (Turney, 2009) is used to describe resurrections in traditional styles, motifs and patterns, and their presentation, construction and promotion through the objects themselves, largely influenced by the landscape, upon which it could be argued much of the textile production in Shetland is based. The notion of heritage knitting draws on craft revivals heavily imbued with notions of nostalgia: In this sense the past is addressed with a sense of loss and nostalgic longing, but often the past was a constructed place of myths, legends, chivalry and harmony, which was created and recreated through literature and the imagination (Turney, 2009).

This turns attention to the way in which rural landscapes in particular and specifically those in Shetland have been situated as sites of consumption through heritage tourism and commoditization, with much of the textile production aimed at the tourist market, including visiting cruise liners. Participants noted that "there has definitely been more (tourism) in the past couple of years" (Creative Practitioner, Shetland Workshop Discussion). Small islands in Northern Europe are often closely associated with a sense of the rural idyll whose signs and symbols relate to particular craft practices, products and lifestyles (Prince, 2017). As a heritage product the landscape is consumed as an extension of a wider social and cultural milieu. This mythological landscape in Shetland includes knitting on two levels: firstly, Fair Isle as part of the iconography and iconology linked to the past, and secondly as vernacular commoditization. The vernacular pertains to a combination of geographic conditions, including locally available materials, environmental concerns, skills, knowledge and local know-how, community beliefs and patterns of behaviour, as well as regionally specific history, tradition and symbolism (Turney, 2009). Tied to the tourist quest for authenticity the commoditization of culture by the means of souvenirs is ubiquitous across island communities (Grydehøj, 2008; Harling Stalker, 2013; Macleod, 2013). Harling Stalker (2013, p. 118) in her exploration of the craft policy of three Atlantic Canadian islands argues that those making crafts on the islands were seen as "producers - disembodied economic entities - that must 
meet the demands of a marketplace, or craftspeople that must perpetuate a romantic ideal to be sold to tourists."

In the Innovation from Tradition workshops participants identified a tension within their practice between creating commoditized products for the tourist market on one hand whilst also aspiring to create higher value products that communicate the value of hand skills to consumers on the other. As Luckman (2012, p. 89) has shown, this often means that practitioners make:

constant trade-offs between the ideal work people wish to be doing and 'bread and butter' work, for example, less expensive, higher turnover items for the tourist trade [...] studio craft producers who were willing to make less challenging and, for them, less interesting but cheap items if it also meant being able to sustain the more rewarding and expensive quality original art pieces.

Innovation from Tradition provided both a provocation and a platform to reimagine creative practice and shared cultural assets. Creative practitioners are invested in their island communities and their rurality on a number of levels, contributing to community resilience through building cultural capital in diverse ways (Roberts \& Townsend, 2015). We posit that this systemic approach could alleviate the time-poor nature of portfolio workers in the creative industries and open up time and space for innovation. One practitioner explained during the workshops that her "vision is to position Fair Isle as a luxury item and bring back the manufacturing of Fair Isle [knitwear] to Fair Isle - from using the local [sheep] clip and spinning we can create bespoke and limited edition artisan Fair Isle, which in turn employ local knitters and encourage young apprenticeships" (Creative Practitioner, Shetland Workshop Discussion). By repositioning away from the lower value tourist market towards higher value exports, she identified a means by which she could maintain authenticity, develop the local skills base and build a more economically viable business.

\section{Place: living wisdom}

Geographical context is fundamental, not incidental, to innovation (Asheim \& Gertler, 2006) and the process of learning through doing. The best way to convey and exchange such knowledge or process wisdom is through demonstration and practice, such as the masterapprentice relationship in which observation, imitation, correction and repetition are employed (Polyani, 1966). This process is at the heart of craft technique and practice in island contexts. As already touched upon, the participants explained during the workshops that one of the assets they were concerned about was "the loss of traditional hand skills" and they articulated concerns about the "retention of craft techniques." Craft practices, which imprint uniqueness into materials, are inherent within the craft and creative processes in island communities.

A deep connection with place exists in the work of practitioners in the creative sector in the Northern Isles. The relationship with the landscape is connected to a creative community of practice (Wenger, 1998) within a geographical context exemplified by shared values, language and culture. In this manner learning through doing can be enacted within a collective social, organizational and cultural context. It is these social processes that are embedded within the physical and environmental character of the islands. Participants reflected on the importance of the natural assets of the islands and island life, invoking ideas around calmness and contemplation alongside wildness and remoteness. Within the Wisdom Wall cards and their reflective conversations, participants spoke of being "surrounded by nature," "the northern lights" and the inspiration of the "vivid light and colours." Inspired by the landscape and light, they explained how they used "shapes, textures, patterns and colours" reflective of the islands "to inspire" their textiles and other creative practices. The 
islands were viewed as a locus of skills and activities connected to cultural heritage. One participant, a Fair Isle knitter, described how "the landscape and the geography is embedded in the tradition of Fair Isle [...] inspired by tradition - crafted for life" (Textiles Practitioner, Shetland Workshop Discussion).

There was a strong sense of Shetland as a place brand, and this was linked to the creative products and services developed there. Participants identified a recent trend for all things Shetland from an interest in island life to the television show Shetland (2013-) and argued that there was a cachet associated with the islands. As one participant explained "so many people are interested in Shetland and it's one of those things, we kind of laugh about it here, the boat almost sails itself' (Textiles Practitioner, Shetland Workshop Discussion). A trend has been identified, particularly amongst Northern European cold-water islands, for greater conformity in how culture is commodified and sold as each island takes part in a quest to differentiate itself as a unique location often in precisely the same ways (Grydehøj, 2008). In her study of the cold-water island destination Bornholm in Denmark, Prince (2017) found that, rather than being imposed, such images were negotiated and constructed by the artists involved as well as policy actors. Whether passively experienced or actively sought after, it is clear that island tourism is frequently driven by a trend to commoditize culture. This experience chimes with the work of Burnett and Danson (2004, p. 391) in relation to food production in Scotland who noted that "the somewhat simplistic representation of rural Scotland within economic policy discourse contrasts with a rather more 'messy', amorphous and complex Scottish rural reality." Amongst participants there seemed to be a relatively bottom-up and organic conception of a Shetland brand without any reference to existing promotional materials or branding campaigns, perhaps significant given the academic critique of past exercises relating to a lack of local involvement in such processes (Grydehøj, 2008). The workshop participants were keen to be involved in such interventions in future and saw a role for themselves in working with Promote Shetland and other actors reminiscent of the more complex stories of negotiated and constructed representations of Bornholm (Prince, 2017). Place identity was seen as something to be capitalized on and taken advantage of, although, as mentioned in the previous section, the exploitation of upturns in tourism was held in tension for creative practitioners and they acknowledged this limited the products they produced.

As well as the richness of assets within the islands, participants were keen to mention the outward facing links that their location in the Northern Islands allowed them to have. In contrast to some of the characterizations of the islands' remoteness, craft practitioners living there connected with textiles collaborators from the US, Norway and Scandinavia. Participants were also keen to mention Shetland Wool Week, an eight-year-old, nine-day series of events and workshops, which takes place across the islands every September, bringing a global profile of visitors and generating more than $\AA^{7} 700,000$ for the local economy in 2017 (Shetland News, 2017). Participants described it as "bringing together textiles companies in Shetland" and "presenting a united front for visitors." As one participant explained, "before the introduction of this annual event, September would have been a period that would traditionally have been the quietest time of year, it is now our busiest time of year" (Creative Practitioner, Shetland Workshop Discussion). These outward connections and promotion of Shetland were also driven by online and digital networks used for networking, sales and image building. As one practitioner noted "on my blog I am getting about 10,000 views a month [...] I don't think I could do any of that without social media" (Creative Practitioner, Shetland Workshop Discussion).

\section{People: collective wisdom}

Things, geography, communities, and people are formed in the meshwork as knots or bundles of social relations (Ingold, 2013). It is the nexus of social relations and social interactions that 
is of interest within developing cultures of innovation. Complex and intangible social contracts and cultures of reciprocity were extremely important within the activities of the participants. This links in part to the role and importance of tacit knowledge, which is the kind of information that is difficult to transfer to another person by means of writing it down or verbalizing it. As an early proponent explained, tacit knowledge reflects the fact that we know more than we can tell (Polanyi, 1966). Effective transfer of tacit knowledge generally requires extensive personal contact, regular interaction and trust. This kind of knowledge can only be revealed through practice in a particular context and transmitted through social networks. For example, one of the collective assets identified by participants on the Wisdom Wall was "the tradition of knitting instruction in primary schools" that had continued up until 2010 before funding cuts. More recently, the Peerie Maakers (young knitters) initiative had introduced intergenerational knitting-focused projects in schools and after-school clubs. The rich and heterogeneous networks and relationships of the participants, identified on the Wisdom Wall, were characterized by deep ties enabling this exchange of tacit knowledge, but perhaps also leading to difficulties in articulating the true value of their practices and exchanges.

These insights point towards the role of a design innovation approach in underpinning the examination and understanding of the complex characteristics of craft and cultural production within an island context. The time spent in developing the networks and engaging with stakeholders was also drawn upon by participants as a key strength, with one commenting:

Certainly, I felt that those hosting the workshop had an appreciation of tradition generally and a strong will to further the development of ideas in many directions. The innovation factor not necessarily having to be a radical departure from some of Shetland's dearly held heritage, more an expansion of it (Creative Practitioner, Shetland Workshop Feedback).

Echoing our model of engagement's initial phases of scoping, network building, and designing appropriate methods, tools, and techniques, there is a need for design researchers to immerse themselves in the contexts and locations they are investigating, work together with local gatekeepers to broker buy-in from the wider community and provide support in managing expectations, dedicate time and space to develop trust with groups, allow for flexibility and deviation in the activities that they coordinate, and design approaches that encourage expression and voice (Ssozi-Mungarua et al., 2017). One participant described how the Wisdom Wall cards helped her "realise that we shared the same needs and views" and the will "to get together and work for a common cause" (Creative Practitioner, Shetland Workshop Feedback). As artefacts created purposely for the Innovation from Tradition workshops, the Wisdom Wall cards enabled craft and creative practitioners to materialize and share their knowledge of local resources and collective cultural assets and to consider how these could be enhanced, reframed, or reappropriated to support the development and sustainability of their own work and its contribution to the creative economy of the region.

There was a significant interest in sharing knowledge and experiences amongst the group rather than a sense that to do so would be problematic for competition. In framing community-based collaborative design as a form of action research in rural communities, Ssozi-Mungarua, Blake, and Rivett (2017) propose that a focus on harnessing collective skills of groups foregrounds the position of research participants and promotes mutual learning and cohesion amongst partnerships. Community-based participatory design connects with publics - groups of people constituted by their connections with a shared issue (Ehn, 2008) - in order to build a network of individuals that may not otherwise exist as a cohesive entity, whilst attending to the social constructs and relations that characterize and permeate these groups (DiSalvo et al., 2012). Manzini (2015, p. 11) proposes that products, services, and models that address societal needs and foster new collaborations "emerge from the creative recombination 
of existing assets (from social capital to historical heritage, from traditional craftsmanship to accessible advanced technology), which aim to achieve socially recognized goals in a new way." By blending the creative and inclusive principles of participatory design with an assetbased mindset, the design innovation approach strengthened the relational nature of the Innovation from Tradition workshops, allowed participants to coalesce around shared challenges and supported them towards establishing themselves as a meshwork of collective wisdom and a community of practice (McHattie et al., 2013).

\section{Conclusions, limitations, and future research}

This article has outlined the rationale for a design innovation approach focused on articulating the value of the collective wisdom and innovative capabilities of island-based craft and creative practitioners. Using such an approach, we developed and carried out a series of workshops with people, practitioners and professionals active in the craft and creative sector in Shetland. By engaging craft practices of making and the materiality of artefacts, such as textiles, we brought diverse groups of people together and rather than focusing on the deficits and challenges faced in working in island locations, this work sought to explore the unique opportunities, resilience and rich history of the island communities. The findings we present are limited in the sense that the Innovation from Tradition workshops were undertaken as an exploratory pilot series. The article contends that a combined approach emphasizing assetbased inquiry (Garven et al., 2016) and participatory design principles (Brandt et al., 2012; Sanders \& Stappers, 2008; Ehn, 2008) can stimulate innovation, which may contribute to more socially equitable models of cultural and economic capital within the creative economy of the Northern Isles of Scotland. Further research will aim to develop future insights around the intersections of practice, place, and people and further investigate the role of a design innovation approach in supporting collective cultural capital and the systemic development of the creative economy within a regional ecology of cultural and economic activities.

\section{Acknowledgements}

With thanks to Professor Irene McAra-McWilliam, the Creative Futures Partnership, and the participants of the Innovation from Tradition workshop series.

\section{References}

Abrams, L. (2006). Knitting, autonomy and identity: the role of hand-knitting in the construction of women's sense of self in an island community, Shetland, c. 1850-2000. Textile History, 37(2), 149-165. https://doi.org/10.1179/004049606x132078

Adamson, G. (2013). The invention of craft. London: Bloomsbury. https://doi.org/10.5040/9781350036123

Adamson, G. (2007). Thinking through craft. London: Berg. https://doi.org/10.5040/9781350036062

Alexander, R. (2016). Migration, education and employment: socio-cultural factors in shaping individual decisions and economic outcomes in Orkney and Shetland. Island Studies Journal, 11(1), 177-192.

Alexander, R. (2015). Career decision making in island communities: applying the concept of the aquapelago to the Shetland and Orkney islands. Shima, 9(1), 38-52.

Asheim, B.T., \& Gertler, M.S. (2006). The Oxford handbook of innovation. Oxford: Oxford University Press. 
Baker, D. (2014). Developing and implementing a robust asset-based approach to public health. Perspectives In Public Health, 134(3), 129-130. https://doi.org/10.1177/1757913914530842

Bilandzic, M., \& Venable, J. (2011). Towards participatory action design research: adapting action research and design science research methods for urban informatics. The Journal of Community Informatics, 7(3).

Black, S. (2012). Knitting. London: V\&A Publishing.

Blackman, C. (1998). Hand knitting in Britain from 1908-39: the work of Marjory Tillotson. Textile History, 29(2), 177-200. https://doi.org/10.1179/tex.1998.29.2.177

Burnett, K.A., \& Harling Starling, L. (2016). 'Shut up for five years': locating narratives of cultural workers in Scotland's islands. Sociologia Ruralis, Online First. https://doi.org/10.1111/soru.12137

Brandt, E., Binder, T., \& Sanders, E.B.N. (2012). Ways to engage, telling, making and enacting. In. J. Simonsen, \& T. Robertson (Eds.) International handbook of participatory design (pp. 145-181). Oxford: Routledge.

Broadley, C., Champion, K., Johnson, M.P., \& McHattie, L.S. (2016). From participation to collaboration: reflections on the co-creation of innovative business ideas. Paper presented to the 50th Anniversary DRS Conference. Brighton, UK: University of Brighton, June.

Chevalier, J.M., \& Buckles, D.J. (2013). Participatory action research: theory and methods for engaged inquiry. London: Routledge.

The Crafts Council (2015). Measuring the craft economy: defining and measuring craft: report 3. London: The Crafts Council.

Crawford, M.B. (2009). Shop class as soulcraft: an inquiry into the value of work. London: Penguin.

DCMS (1998). Creative industries mapping document: crafts. London: DCMS.

DiSalvo, C., Clement, A., \& Pipek, V. (2012). Participatory design for, with, and by communities. In. J. Simonsen \& T. Robertson (Eds.) International handbook of participatory design (pp. 182-209). Oxford: Routledge.

Dorst, K. (2015). Frame innovation: create new thinking by design. Cambridge: MIT Press.

Ehn, P. (2008). Participation in design things. Paper presented at the tenth anniversary conference on participatory design. Indiana, USA: Indiana University Bloomington, October.

Foot, J., \& Hopkins, T. (2010). A glass half full: how an asset approach can improve community health and wellbeing. London: Improvement and Development Agency.

Frayling, C. (2017). On craftsmanship. Oberon Books: London.

Frayling, C. (1993). Research in art and design. Royal College of Art Research Papers, 1(1), 1-5.

Garven, F., McLean, J., and Pattoni, L. (2016). Asset-based approaches: their rise, role, and reality. Dunedin Academic Press: Edinburgh.

Glasgow Centre for Population Health \& Scottish Community Development Centre (2015). Positive conversations, meaningful change: learning from animating assets. Glasgow Centre for Population Health. http://www.gcph.co.uk/publications/598 positive conversations meaningful chang e learning from animating assets

Grydehøj, A. (2010). Uninherited heritage: tradion and heritage production in Shetland, Åland and Svalbard. International Journal of Heritage Studies, 16 (1-2), 77-89. https://doi.org/10.1080/13527250903441796

Grydehøj, A. (2008). Branding from above: generic cultural branding in Shetland and other islands. Island Studies Journal, 3 (2), 175-198. 
Grydehøj, A., Pinya, X., B., Cooke, G., Doratl, N., Elewa, A., Kelman, I., Pugh, J., Schick, L., and Swaminathan, R.. (2015) Returning from the horizon: introducing urban island studies. Urban Island Studies, 1, 1-19. https://doi.org/10.20958/uis.2015.1

Harling Stalker, L. (2013). But who crafted the craftspeople? Examining craft policy on three Atlantic Canadian islands. Shima, 7(1), 106-120.

HIE (2013) Creative industries strategy 2014-2019. Highlands and Islands Enterprise. http://timeline.hie.co.uk/media/1361/creative-industriescreativeplusindustriesplusstrategy.pdf

Housden, P. (2014). This is us: a perspective on public services in Scotland. Public Policy and Administration, 29(1), 64-74. https://doi.org/10.1177/0952076713513993

Howard, Z., \& Somerville, M.M. (2014). A comparative study of two design charrettes: implications for codesign and participatory action research. CoDesign, 10(1), 46-62.

Ingold, T. (2013). Making. London: Routledge. https://doi.org/10.1080/15710882.2014.881883

Jakob, D., \& Thomas, N.J., (2015). Firing up craft capital: the renaissance of craft and craft policy in the United Kingdom. International Journal of Cultural Policy, 23(4), 495-511. https://doi.org/10.1080/10286632.2015.1068765

Johnson, M.P., Champion, K., McHattie, L.S., \& White, G. (2016). Beyond the bottom line: redefining the value of design in sme formation. Paper presented to the DMI: Academic Design Management Conference. Boston, USA: Massachusetts College of Art, July.

Kearney, G., \& McHattie, L.S. (2014). Supporting the innovation process in small and medium enterprises. International Journal of Entrepreneurship and Small Business, 23(4), 552-567. https://doi.org/10.1504/IJESB.2014.065680

KPMG (2016). Innovation through craft: opportunities for growth, A report for the Crafts Council. London: KPMG.

Luckman, S. (2018). Cultural policy and creative industries. In. V. Durrer,T. Miller, \& D. O'Brien (Eds.) The Routledge handbook of global cultural policy (pp. 341-355), London: Taylor and Francis.

Luckman, S. (2015). Craft and the creative economy. New York: Palgrave Macmillan. https://doi.org/10.1057/9781137399687

Luckman, S. (2013). The aura of the analogue in a digital age; women's crafts, creative markets and home-based labour after etsy. Cultural Studies Review, 19(1), 249-70. https://doi.org/10.5130/csr.v19i1.2585

Luckman, S. (2012). Locating cultural work: the politics and poetics of rural, regional and remote creativity. London: Palgrave Macmillan. https://doi.org/10.1057/9781137283580

Manzini, E. (2015). Design, when everybody designs: An introduction to design for social innovation. Cambridge: MIT Press.

Markusen, A. (2007). An arts-based state rural development policy, special issue on state rural development policy. The Journal of Regional Analysis and Policy, 37(1), 7-10.

Matarasso, F. (2012). Stories \& fables: reflections on culture development in Orkney. Parliament of Dreams. https://parliamentofdreams.com/2012/01/23/stories-and-fables-culture-in-orkney/

McAra-McWilliam, I. (2017). The Glasgow School of Art Winter School 2017. https://vimeo.com/207442266

McAra-McWilliam, I. (2009). The distributed city. In S. Wright, J. Newbigin, J. Kieffer, J. Holden, \& T. Bewick (Eds.) After the crunch (pp. 70-71), Edinburgh: Creative \& Cultural Skills; Counterpoint.

McHattie, L.S., MacLean, D., \& Dixon, B. (2013). Design innovation: experimental creative research approaches. Paper presented to the IASDR 2013 Conference. Tokyo, Japan, August.

Macleod, D. (2013). Cultural realignment, islands and the influence of tourism: a new conceptual approach. Shima, 7(2), 74-91. 
National Records of Scotland (2017). Shetland Islands Council area demographic factsheet, National Records of Scotland. https://www.nrscotland.gov.uk/files/statistics/council-area-datasheets/shetland-islands-factsheet.pdf

Nesta (2007). Rural Innovation. London: NESTA.

Norman, D.A., \& Verganti, R. (2014). Incremental and radical innovation: design research vs. technology and meaning change. Design Issues, 30(1), 78-96. https://doi.org/10.1162/DESI a 00250

Polanyi, M. (1966). The tacit dimension. London: Routledge.

Prince, S. (2017) Rural authenticity and agency on a cold-water island: perspectives of contemporary craft-artists on Bornholm, Denmark. Shima, 11(1), 103-121.

Roberts, E., \& Townsend, L. (2016). The contribution of the creative economy to the resilience of rural communities: Exploring cultural and digital capital. Sociologia Ruralis, 56(2), 197- 219. https://doi.org/10.1111/soru.12075

Sanders, E.B.N., and Stappers, P.J. (2014). Probes, toolkits and prototypes: three approaches to making in codesigning. CoDesign, 10(1), 5-14. https://doi.org/10.1080/15710882.2014.888183

Sanders, E.B.N., and Stappers, P.J. (2008). Co-creation and the new landscapes of design. CoDesign, 4(1), 5-18. https://doi.org/10.1080/15710880701875068

Scott, K., \& Marr, M. (2012). Shetland textiles sector: a review. Shetland Islands Council. https://www.shetland.gov.uk/economic development/documents/ShetlandTextileRe viewFinalReport.pdf

Sennett, R. (2009). The Craftsman. London: Penguin.

Shetland News (2017). Wool week provided f,700k economic boost to islands. Shetland News, 13 December. http://www.shetnews.co.uk/newsbites/15636-wool-weekprovided-700k-economic-boost-to-islands

Ssozi-Mugarura, F., Blake, E., and Rivett, U. (2017). Codesigning with communities to support rural water management in Uganda. CoDesign, 13(2), 110-126. https://doi.org/10.1080/15710882.2017.1310904

Steen, M. (2011). Tensions in human-centred design. CoDesign, 7(1), 45-60. https://doi.org/10.1080/15710882.2011.563314

Thompson, C. J., \& Haytko, D. L. (1997). Speaking of fashion: consumers' uses of fashion discourses and the appropriation of countervailing cultural meanings. Journal of Consumer Research, 24(1), 15-42. https://doi.org/10.1086/209491

Turney, J. (2009). The culture of knitting. London: Berg.

Vaajakallio, K. (2009). Enacting design: understanding co-design as embodied practice. Paper presented to the Nordes 2009 Conference. Oslo, Norway: The Oslo School of Architecture and Design, August.

Wenger E. (1998). Communities of Practice: Learning, Meaning and Identity. Cambridge: Cambridge University Press. https://doi.org/10.1017/CBO9780511803932

Yair, K. (2011). Craft and rural development. London: Crafts Council. 